\title{
Regular Features
}

\section{Hotels}

\section{Hotel investment risk: What are the chances?}

Received (in revised form): 7 November 2006

\section{Elie Younes}

was, at the time of writing, a Director with HVS International's London office, heading the Middle East and Africa region together with Bernard Forster. He joined HVS International in 2001 having had four years' operational and managerial experience in the hospitality industry in the Middle East. He holds a BA in Hospitality Management from Notre Dame University in Lebanon, an MBA from IMHI (Essec Business School, France and Cornell University, USA) and is currently preparing his MSc in Real Estate Investment at Cass Business School in London. He has now joined Starwood Hotels and Resorts' Acquisition \& Development team.

\section{Russell Kett}

is Managing Director of the London office of HVS International. He has some 30 years' specialist hotel consultancy, investment and real estate experience and generally focuses on the provision of valuation, feasibility, shared ownership, property, brokerage, investment, asset management, strategy and related consultancy services, advising hotel companies, financial institutions, developers and investors on all aspects of their hospitality industry-related interests, throughout Europe, the Middle East, Africa and Asia. He is a frequent speaker on the international hotel industry and on topics relating especially to the valuation of and investment in hotels, marketing, resorts and shared ownership, as well as on the hospitality sector generally. He lectures regularly at leading international hotel schools including Cornell University, the Scottish Hotel School, University of Strathclyde, Oxford Brookes University, Ecole Hôtelière de Lausanne and IMHI-Essec in Paris.

\begin{abstract}
So, what is riskier: investment in a limited service hotel, full service hotel, serviced apartments/extended stay or shared ownership property? Should a mortgage of a limited service hotel be structured in a similar way to that of a full service hotel or other type of hotel asset, or should some distinctions be considered given the nature of each asset class?
\end{abstract}

\section{Keywords:}

development risk, shared ownership property, operating risk, exit risk,

Russell Kett HVS International London 7-10 Chandos Street Cavendish Square London W1G 9DQ, UK Tel: +442078787701 Fax: +442078787799 E-mail: rkett@hvsinternational.com
Journal of Retail and Leisure Property (2007) 6, 69-78. doi:10.1057/palgrave.rlp.5100049

\section{HOTEL LIFECYCLE AND RISK COMPONENTS}

In line with any type of real estate investment (and probably any investment!), a hotel's lifecycle has three main phases: development, operation and exit. 


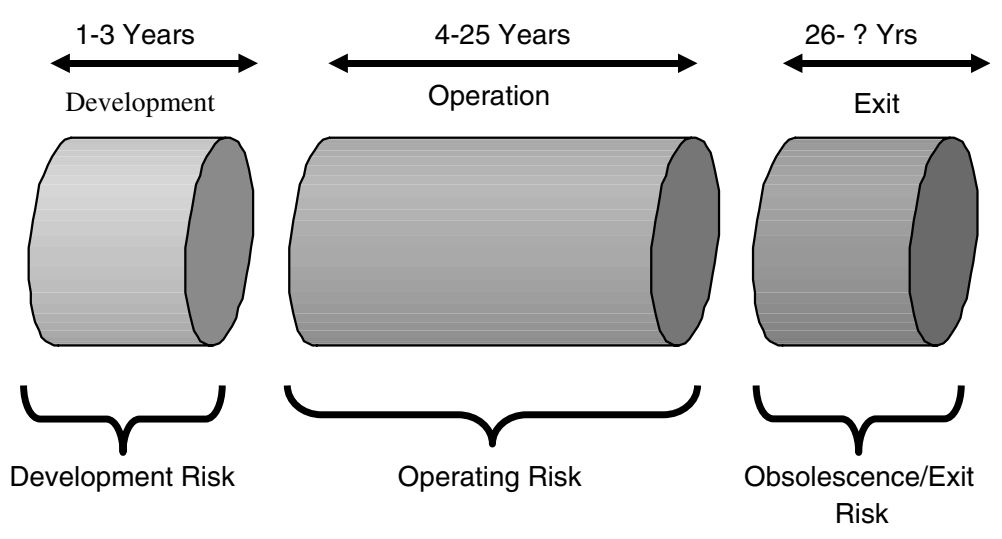

Figure I: Hotel life cycle and investment risk factors

It takes approximately one to three years to develop a hotel asset (depending on the type of property), and a typical investor would hold the asset for a period of between five and 25 years. At the end of the lifecycle (or holding period), an investor would sell the property or redevelop it; a process that takes a minimum of one year and may, infrequently, never materialise.

Consequently, and as illustrated in Figure 1, a hotel investment inherits three categories of risk that are directly attributable to the main phases of its lifecycle: development risk, operating risk and obsolescence/exit risk.

\section{Development risk}

Development risk is the economic threat that a developer/investor is exposed to upon converting a vacant piece of land or an existing building into a fully operational hotel asset. Obviously, the more complicated the type of asset is, the higher the development risk would be. In other words, this risk is the probability that a setback takes place during the development process that has a negative effect on the development cost or any aspect that influences the future investment returns (location of the asset, positioning, type of operator, physical characteristics, construction and design, timing of completion, capital structuring and so forth). There is sometimes a great difference between how a hotel asset should look and how it actually does when it is built!

Table 1 illustrates the main elements/steps (and hence the risk elements) that are required to develop a hotel asset. Developing hotels is highly capital intensive and requires the ultimate harmony between all parties involved in order to secure an economically viable investment. Any setback during the development would severely impact the investment returns.

Full service and luxury hotels are, by nature, complicated hotels to develop, when compared to other hotel assets. Such properties require more time to develop, necessitate complicated space planning and design, are highly capital intensive and face high market expectations in terms of the physical product offering (which, again, makes it increasingly critical for the developer to ensure an appropriate end product). Therefore, such 
Table I: Main steps in developing a hotel asset

Main risk elements of a hotel development

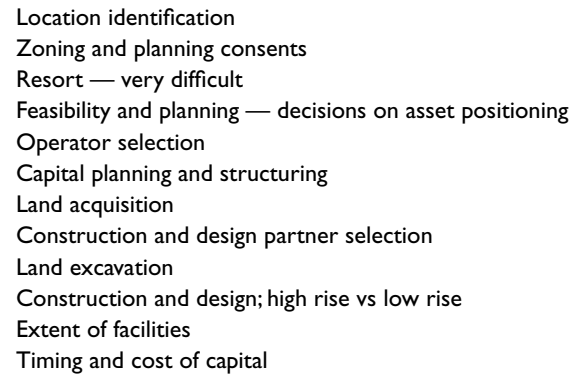

an asset class is exposed to a high level of development risk when compared to other hotel derivatives.

As with full service hotels, serviced apartments/extended stay units have different 'grades' that span the budget, mid-market and luxury sectors. In general, all can be said to provide more spacious accommodation than traditional hotel rooms of a similar standard, with the benefit of kitchen facilities allowing for self-catering. While such an asset class is less complicated to develop than full service/luxury hotels, given its limited amount of public space, such properties (irrespective of their grade) are more complicated to develop when compared to limited service/budget hotels.

Shared ownership properties vary widely in terms of product offering, grade and so forth. For example, products range from an upmarket timeshare development in a beach resort (hence requiring complicated designs, space planning and so forth) to condominium units (second home/residential/investment) in a city (which are easier to develop). Therefore, the development risk associated with this asset class varies considerably. For the purpose of this paper, we have assumed that this asset class is prone to a medium level of development risk, when compared to other hotel derivatives.

Figure 2 summarises the relative level of development risk of each asset class within the industry.

\section{Ownership's operating risk}

The total 'holding period return' of any type of investment is the combination of the cash flow earned throughout the holding period as well as the capital appreciation (or depreciation) of the asset. Depending on the type of hotel property (and its holding period), the operating cash flow returns represent between 30 and 70 per cent of the overall returns. Typically, the operating risk of a hotel asset is higher during the first years of operation of the property, when compared to the level of risk attributed to its operation once it reaches a stabilised level of trading performance.

The operating risk is simply the ability of the asset (and its management) to generate sufficient levels of cash flow in order to produce 


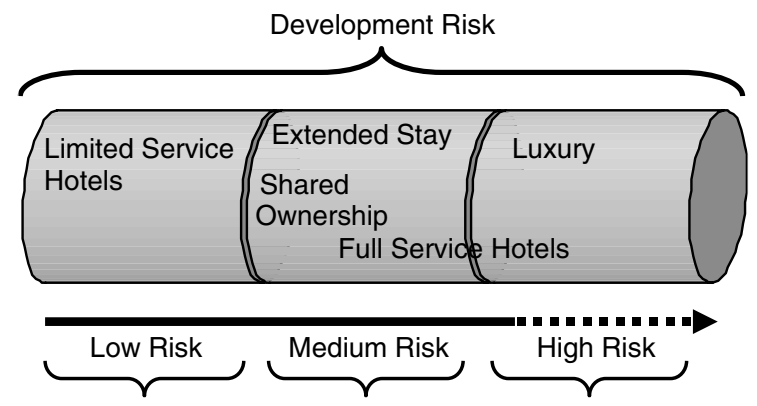

Figure 2: Development risk

a certain level of financial returns to justify the investment and/or catalyse an exit.

Owners are significantly exposed to the operating risk in a hotel investment. Any fluctuation in the operating performance of a hotel asset has a significant impact over the net operating income available to its owner to service the hotel mortgage/senior debt and secure a level of capital to justify a return on the investment. A severe economic downturn, for example, could potentially force the business (and its owner) into liquidation and result in a lender's step in, pulling the owner out of business. Obviously, the uplift is equally positively rewarding.

The main operating risk factor in a hotel property is the volatility of its net operating income (EBITDA) throughout the holding period. The more the net operating income is likely to fluctuate over a specific period of time, the higher the operating risk. As can be seen in Figure 3, while both Hotel Asset 1 and Hotel Asset 2 achieved an average annual net operating income of approximately $€ 800,000$ over ten years, Asset 2 achieved a more stable (and predictable) level of cash flow throughout this period. This implies that the operating risk of Asset 2 is lower than that of Asset 1.

Given the operating structure of a hotel asset, this risk can be attributed to two main characteristics: revenues and the fixed cost structure of the operation. Various dynamics and business characteristics, whether controllable or uncontrollable, impact on these operating risk factors.

There are fundamental operating differences between the various types of hotel asset. For example, while a conventional full service hotel typically requires a balanced and broadly based business mix (segmentation), an extended stay property is less dependent on such an operating dynamic. Furthermore, while the room inventory of a full service hotel is highly perishable (each room needs to be sold to different guests on a continuing basis), an extended stay unit inventory is less perishable given the long average length of stay of such an asset class (in both cases, however, you cannot sell yesterday's available room!). Other operating differences include the fact that the fixed cost structure of a full service hotel operation is greater than that of a limited service hotel or an extended stay property (due to food and beverage facilities, revenue mix, service quality expectations and so forth). Moreover, our assessment of historical trading data of various hotel categories and classifications suggests that limited service hotels and extended stay units tend to be 


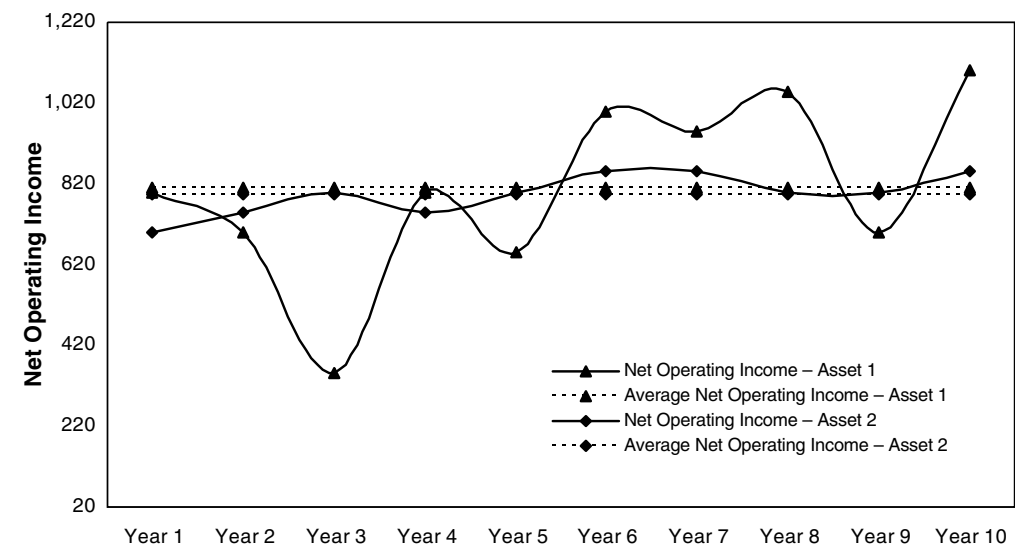

Figure 3: Illustration of operating risk (€ 000s)

less vulnerable to economic shocks and external factors than full service and luxury hotels.

Some of the external factors that also impact the operating performance of a hotel asset include the demand and supply dynamics in a given market, as well as the barriers of entry for a specific asset class. An overly supplied market will undoubtedly hamper the trading performance of a hotel asset. Yet, barriers of entry such as scarcity of land, capital liquidity, zoning restrictions, planning regulations, bureaucracy and so forth typically serve as a hedge against such a risk. While most hotel asset classes are equally exposed to this risk, one could argue that full service hotels tend to be, on occasions, hedged against that risk due to the barriers of entry associated with this asset class.

In terms of the shared ownership asset class, despite the cash flow volatility of such a business model, the operating risk of this type of hotel derivative is considerably reduced (to the original developer/investor), as the room inventory is typically sold before (or upon) completion of the development, which either transfers this risk to the individual owners of the units or significantly dilutes/eliminates this risk. The level of return associated with the operation of a shared ownership property is lower than that of other asset classes (between 10 and 20 per cent of total holding period returns), given the initial inventory exit/sale of the units. Therefore, the operating risk of a shared ownership development is minimal (unless the developer provides guaranteed returns), from the original developer's perspective.

Figure 4 summarises the relative level of operating risk of each asset class within the industry.

\section{Obsolescence/exit risk}

This risk impacts the ability of the owner of the hotel property to exit the investment or extend its economic life. This risk involves the potential decrease in a property's value as at the envisaged exit period. It is the uncertainty of the future value of the hotel asset.

Obsolescence is an incurable economic depreciation that has a considerable impact on the holding period returns of a hotel asset 


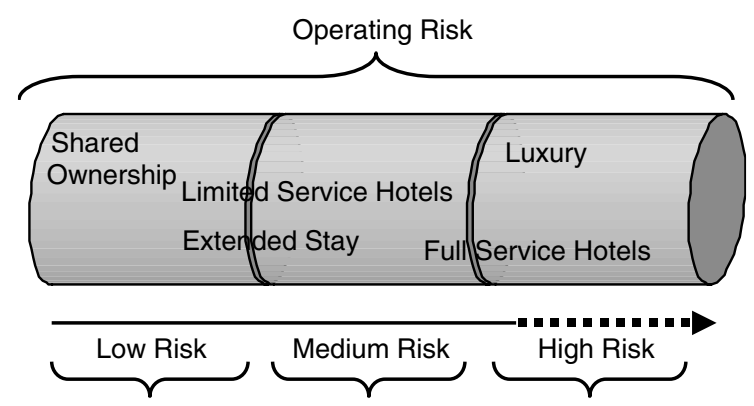

Figure 4: Operating risk

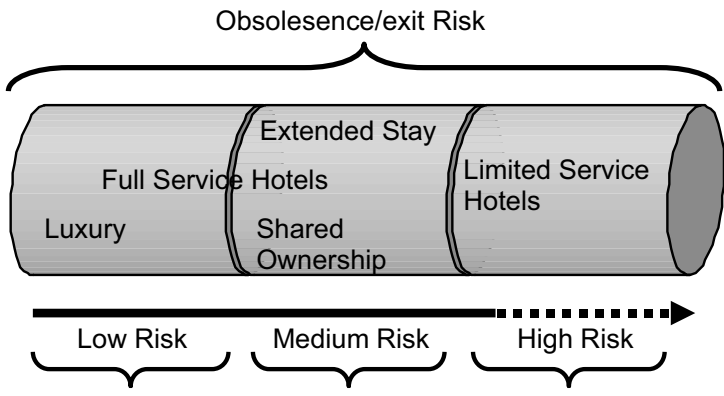

Figure 5: Obsolescence/exit risk

(Figure 5). There are various types of obsolescence that can impact hotel real estate but generally they are classified as either internal or external obsolescence.

\section{Internal obsolescence}

Typically this is functional obsolescence that occurs when a hotel no longer functions/operates the way it did when it was initially built; it is a change in the fitness for purpose. This includes the physical deterioration of the building, which can be either curable via repairs and capital expenditure or incurable if the basic structure of the building has been heavily damaged over time. While most types of physical deterioration of a hotel asset can be curable, sometimes it makes no economic sense to do so. For example, while the physical deterioration of the external appearance (exterior, public areas and so forth) or the internal specifications (services, finishes and so forth) can be cured, the property can become obsolete if the configuration of the building is no longer appropriate (style, plan layout, floor to ceiling heights, structural damages and so forth). In general, most hotel assets are equally prone to this type of obsolescence; however, service/budget hotels are more exposed to this risk given the initial economical approach to the building and low-cost layout/structure.

\section{External obsolescence}

This is the loss in income and value resulting from external factors. Various economic, demographic, environmental, legal and social factors may impact the economic viability of a hotel which may not be curable. 
For example, new legislation regarding safety may render a property obsolete if it impacts the layout of the hotel. A shift in the economic, demographic or social gravity of the immediate area of the hotel can also render a property obsolete, especially if the hotel is located in a secondary location (as is usually the case with limited service and budget hotels with the aim to reduce the initial cost of land to boost economic viability) or if the area in which it was originally built migrates from primary to secondary over time.

Given the structural design, layout, building structure, style and location of limited service hotels, they are exposed to the highest risk of internal and eternal obsolescence when compared to other types of hotel properties. Extended stay properties are less exposed to obsolescence risk than limited service hotels (given their typical locations, layout and so forth), but are more exposed to this risk than full service and luxury hotel assets (especially from a 'fitness for purpose' perspective).

The success of a shared ownership property investment depends heavily on the ability of the developer to sell the units during the development phase (or during the few years following the completion of the development). Therefore, this risk factor has a dual risk potential (in terms of its impact on investment returns) when compared to other asset classes: while the property itself may not become physically obsolete after a period of time, given the emerging nature of the shared ownership sector, the complexity of the exit process (heavy administrative and marketing overheads) and the heterogeneity of potential investors this asset class inherits a high level of exit risk. This exit risk occurs in two phases: initial exit of the units and exit upon transfer of ownership back to the developer in Year 20 or thereafter.

\section{Synthesis and implications}

Based on the previous analysis, Figure 6 summarises the relative levels of risk factors for the main types of hotel assets throughout their economic lives.

Various asset classes within the hotel sector have different risk profiles throughout their cycles. While full service and luxury hotels inherit higher levels of development and operating risks than limited service and extended stay properties, upscale hotel properties are less exposed to the obsolescence/exit risk. Furthermore, while shared ownership developments have a lower operating risk than other hotel derivatives, this asset class probably inherits a high exit risk.

Therefore, the fundamental differences in the various asset classes have different implications for their investment evaluation, lending characteristics and asset management.

Typically, when evaluating a hotel investment, one would project the property's cash flow over a specific period of time, and would then apply various financing parameters to assess the value of the investment in today's prices. Usually, a property yield is applied to those cash flows in order to compute the investment value of the asset as at a specific date.

The property yield is usually the combination of the cost of capital as well as the potential property appreciation or depreciation. Practically, the main variables that form the property yield include the cost of debt, the 


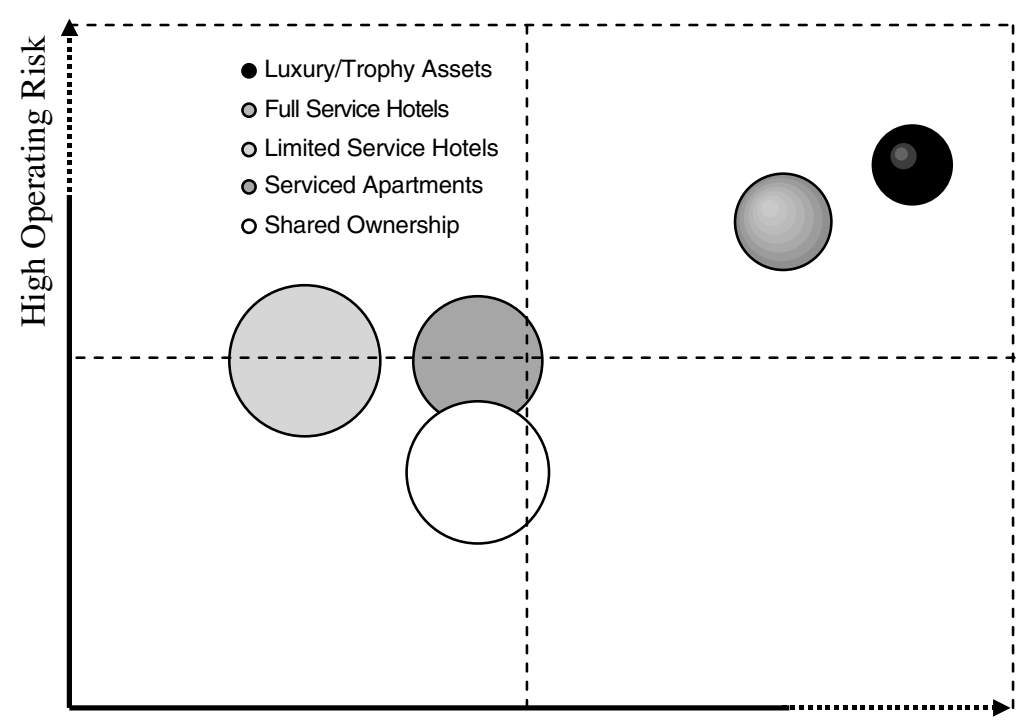

High Development Risk

Figure 6: Risk matrix for the hotel industry

Note: The width of the spheres indicates the obsolescence rise.

cost of equity, an optimum/market specific financing structure and a terminal capitalisation rate (the residual/reversionary value upon exit). These variables each impact the various time cycles in the cash flow differently, as can be seen in Table 2 .

The simplified illustration of an investment assessment, as shown in Table 2, reflects the following:

- The developer's profit reflects the development risk associated with that phase; the higher the development risk, the greater the required profit percentage. Upon making investment decisions, the total development cost (including developer's profit — and taking into account the development risk) is then compared with the net present value of the cash flow (taking into account the time value of money).

- The cost of capital is typically applied to the operating cash flow during the holding period as well as upon discounting the exit/ residual value of the investment to Year 1 . This parameter reflects the operating risk (and other risks inherited from the development phase) of a hotel asset. A high operating risk would fuel the debt and equity yields and would therefore imply a higher weighted cost of capital.

- The terminal capitalisation rate reflects the value of a hotel property at exit, taking into account economic cycles as well as capital appreciation/depreciation. In a conventional valuation, this rate is usually the adjusted cost of capital less inflation. In practice, however, the terminal capitalisation rate can fluctuate in order to reflect future capital appetite, yield compressions, cycles or, in some instances, obsolescence. A higher obsolescence risk in an asset class would therefore necessitate a higher terminal capitalisation rate (hence a lower exit value). 


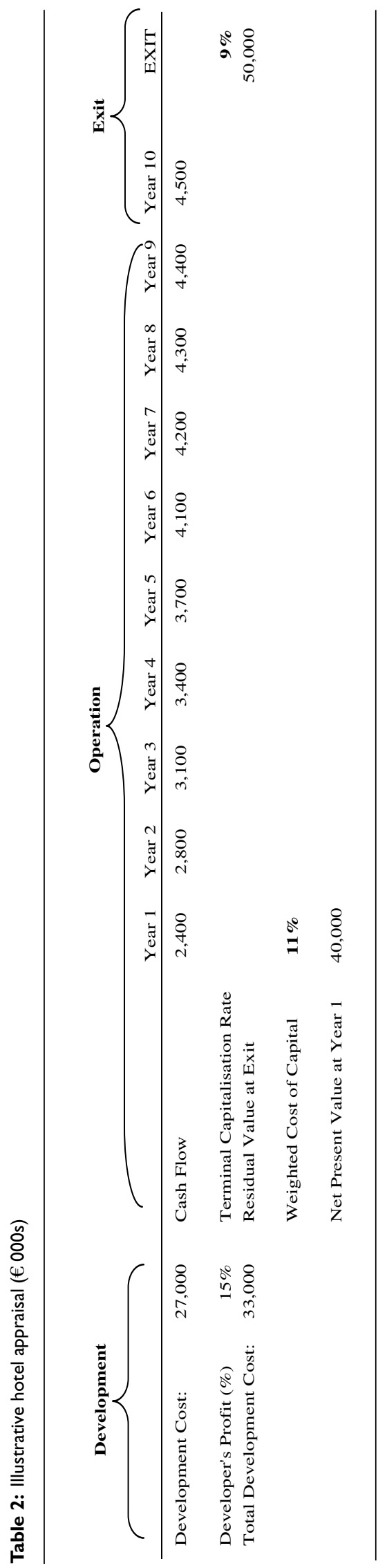


Assuming identical market and economic conditions and based on the preceding assessments, we make the following observations:

- A lower developer's profit (in percentage and quantum) could be applied to extended stay properties and limited service hotels, when compared to full service and luxury hotel assets, given their lower development risk.

- A lower cost of capital could be applied to extended stay and limited service hotel properties, when compared to full service and luxury hotel assets, in order to reflect their lower operating risk profile.

- Given the lower exit risk of five-star and luxury hotels, a lower terminal capitalisation rate should therefore be applied to this type of hotel property, when compared to limited service and extended stay properties.

- Due to the comparatively higher obsolescence risk of limited service/ budget hotels, it should be no surprise when lenders resist long-term bullet/balloon financing for such an asset class.

- While the asset manager of a typical full service/luxury hotel continuously aims at maximising the value of the hotel asset and improving its operating cash flow, the asset management objective of limited service or extended stay properties should mainly focus on maximising the operating cash flow throughout the economic life cycle of the asset.

Unfortunately, no generalisation can be made or concluded in terms of what is the safest or least risky type of hotel property to invest in, given the various risk profiles of the asset classes throughout their economic cycle. It is certain, however, that risk diversification can be achieved within the industry (from a portfolio perspective or by combining two or more asset classes within one development), which would enhance the risk-adjusted returns to the owners.

We would highlight that this approach of risk assessment is theoretical/ fundamental, and that various market dynamics as well as characteristics and levels of investor appetite must always be considered upon appraising a hotel property. Capital markets can have diverse characteristics and risk profiles and would oftentimes view the risk of a hotel investment differently; a fact that must always be considered upon appraising an investment, as long as it represents the market participants. As in the theory of equity markets, the 'market efficiency' of the hotel transaction sector is a debatable topic.

Finally, we emphasise that the specific risk associated with any individual hotel investment is determined by the characteristics of that investment, including location, property, ownership, management and so forth.

Various hotel investors have different risk profiles, investment appetite and stimulants as well as perception of time. Once these are better understood, the hotel asset classes and risks can then be chosen!

(C) HVS International 